\title{
A Reliable Seawater Desalination System Based on Membrane Technology and Biotechnology Considering Reduction of the Environmental Impact
}

\author{
Masaru Kurihara ${ }^{1, *}$, Hiromu Takeuchi ${ }^{1}$ and Yohito Ito ${ }^{2}$ \\ 1 Toray Industries, Inc., 2-1-1 Nihonbashi-muromachi, Chuo-ku, Tokyo 103-8666, Japan; \\ Hiromu_Takeuchi@nts.toray.co.jp \\ 2 Toray Industries, Inc., 3-2-1 Sonoyama. Otsu, Shiga 520-0842, Japan; Yohito_Ito@nts.toray.co.jp \\ * Correspondence: Masaru_Kurihara@nts.toray.co.jp; Tel.: +81-3-3245-5716
}

Received: 31 October 2018; Accepted: 27 November 2018; Published: 3 December 2018

\begin{abstract}
The application of seawater desalination technology using a reverse osmosis (RO) membrane has been expanding because it requires less energy compared with other distillation methods. Even in Middle Eastern countries where energy costs are lower such as Saudi Arabia, UAE, Qatar, and Kuwait, almost all desalination plants where only water production is required have adopted the RO method. However, large plants in excess of half mega-ton size are required, and Seawater Reverse Osmosis (SWRO) operation lacks reliability due to heavy biofouling and large amounts of briny discharge contaminated with chemicals. For reliable desalination systems with lower environmental impact, membrane-processing technology, including biotechnology (such as marine bacteria), has been examined as national research in Japan in the "Mega-ton Water System" project. We examined the influence of chlorination on marine bacteria using the fluorescence microscopic observation method and found that the effect of chlorination is limited. Chlorination sterilization triggers biofouling and sodium bisulfate (SBS) addition as a de-chlorinating agent also triggers biofouling, so a process with no chlorine or SBS addition would reduce biofouling. As polyamide SWRO membranes have low chlorine resistivity, such a process would enable longer membrane life in real plants. We used a biofouling monitoring technology, the Membrane Biofilm Formation Rate (mBFR), to design a process that involves no chlorine or SBS addition and verified it in the Arabian Gulf Sea, of Saudi Arabia, which is one of the most difficult and challenging seawaters in which to control biofouling. Furthermore, by minimizing the addition of a sterilizer, the desalination system became more environmentally friendly.
\end{abstract}

Keywords: biofouling monitoring technology; membrane biofilm formation rate; trigger of biofouling; marine bacteria; seawater desalination

\section{Introduction}

Seawater desalination plants applying the distillation process began operation in the mid-1960s. Since 2000, application of the energy saving RO (Reverse Osmosis) membrane process has surpassed the distillation process except in the Middle East, where major large seawater desalination plants still use the distillation process [1]. As shown in Figure 1 which was prepared in 2009, the scale of desalination plants have been increasing. Thus, we predicted that ultra-large plants of the mega-ton per day scale $\left(1,000,000 \mathrm{~m}^{3} /\right.$ day) would be required by 2020 . The construction of many ultra-large plants over the 500,000 $\mathrm{m}^{3}$ / day started in 2017-2018 in the Middle East and North Africa (MENA country). MENA countries have recently decided to use the RO membrane process instead of the distillation process, such as multi-stage flash (MSF) and multi-effect distillation (MED) due to the 
lower energy consumption of plants. Therefore, mega-ton $\left(10,000,000 \mathrm{~m}^{3} /\right.$ day) size plants adopting the SWRO (Seawater Reverse Osmosis) method are expected to be developed soon ( Figure 1).

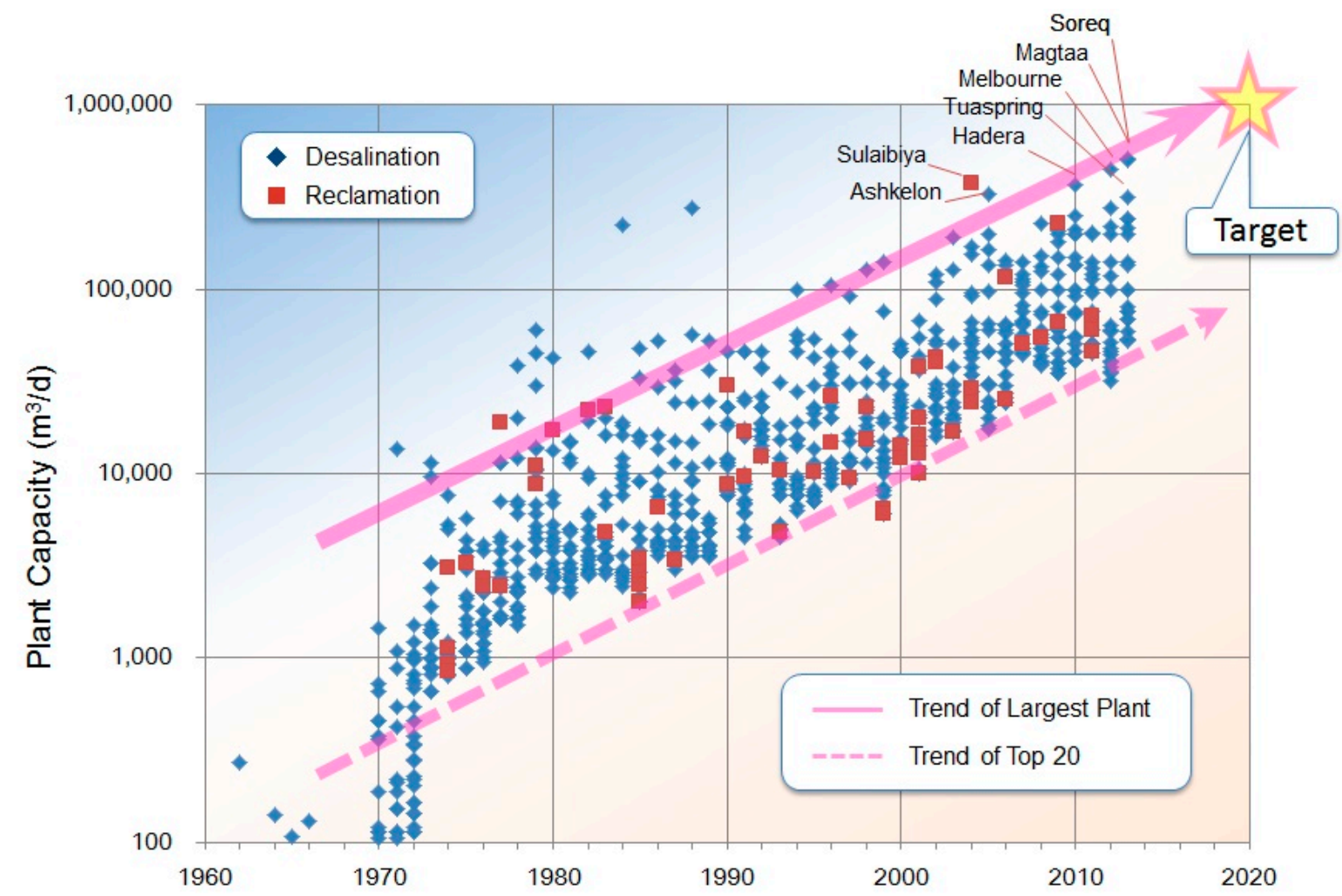

Figure 1. Change in RO (Reverse Osmosis) plant size of desalination and reclamation.

Seawater desalination in the 21st century requires: (1) Energy resources, (2) Seawater RO system, and (3) Desalination drainage to reduce marine pollution. Japan's national research project, the "Mega-ton Water System," was conducted with the aim of developing sustainable water treatment core technologies necessary for the 21st century. The missions of the project were: (1) energy saving $(20 \%$ or $30 \%)$, (2) low environmental impact (no chlorine dosing), (3) low water production cost, and (4) reliable plant operation, as illustrated in Figure 2 [2].

The "Mega-ton Water System" project envisions sustainable desalination and reclamation.

With the rapid spread of seawater desalination plants, operational problems have increased due to the poor design of the plant systems and improper operating conditions. Therefore, along with facility cost reduction, technology should be improved to enable reliable plant operation by preserving facility specifications [2,3]. For this reason, Japan's national research Funding Program for World-Leading Innovative Research \& Development on Science and Technology (FIRST Program) promoted in-depth research of water treatment core technologies, the "Mega-ton Water System", and included research on basic and system technologies [2,3].

The research themes of the "Mega-ton Water System" project were as follows [2,3]:

1. Low-pressure SWRO membranes.

2. Next generation energy recovery devices (ERD).

3. Low-pressure multistage SWRO systems (LMS): SWRO Plant Image Integrated by Mega-ton Technologies.

4. Energy Recovery from SWRO Brine by PRO (pressure-retarded osmosis)

5. New high durability high-pressure resin pipes.

6. Biofouling monitoring technology: Bacterial Community Composition Change by Chemical. 
The output of the "Mega-ton Water System" were six indispensable technologies for the 21st century, and these are summarized in Figure 3. In order from left to right, in the top row, (6) Bacterial Community Composition Change by Chemical is related to the biofouling monitoring technology, (3) SWRO plant image integrated by Megaton Technologies, and (2) next-generation energy recovery device. Similarly, in the bottom row, (1) low-pressure SWRO membrane, (5) new high-pressure resin pipes, and (4) energy recovery from SWRO brine by pressure-retarded osmosis (PRO).

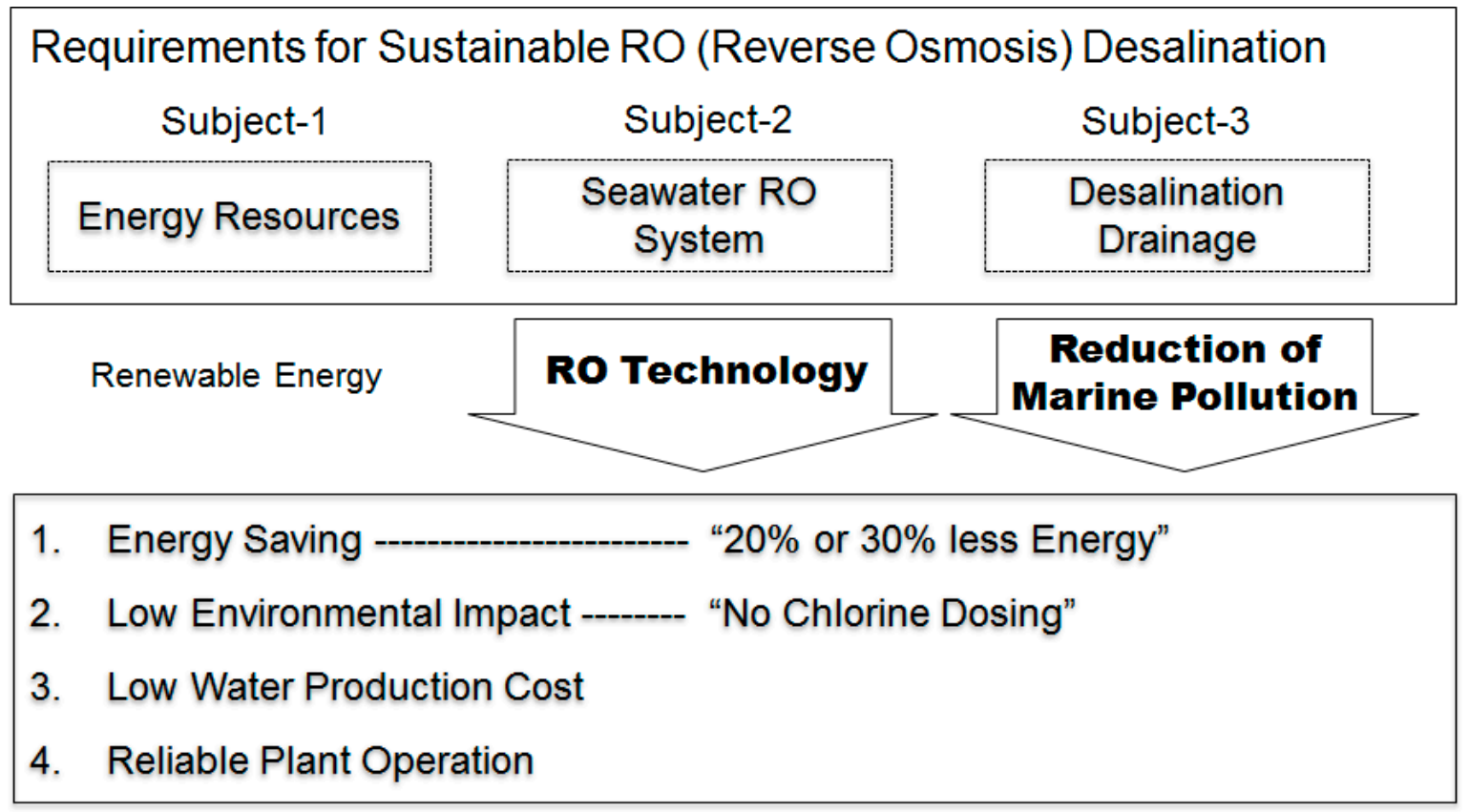

Figure 2. Requirements for sustainable RO (Reverse Osmosis) desalination in the 21st century.

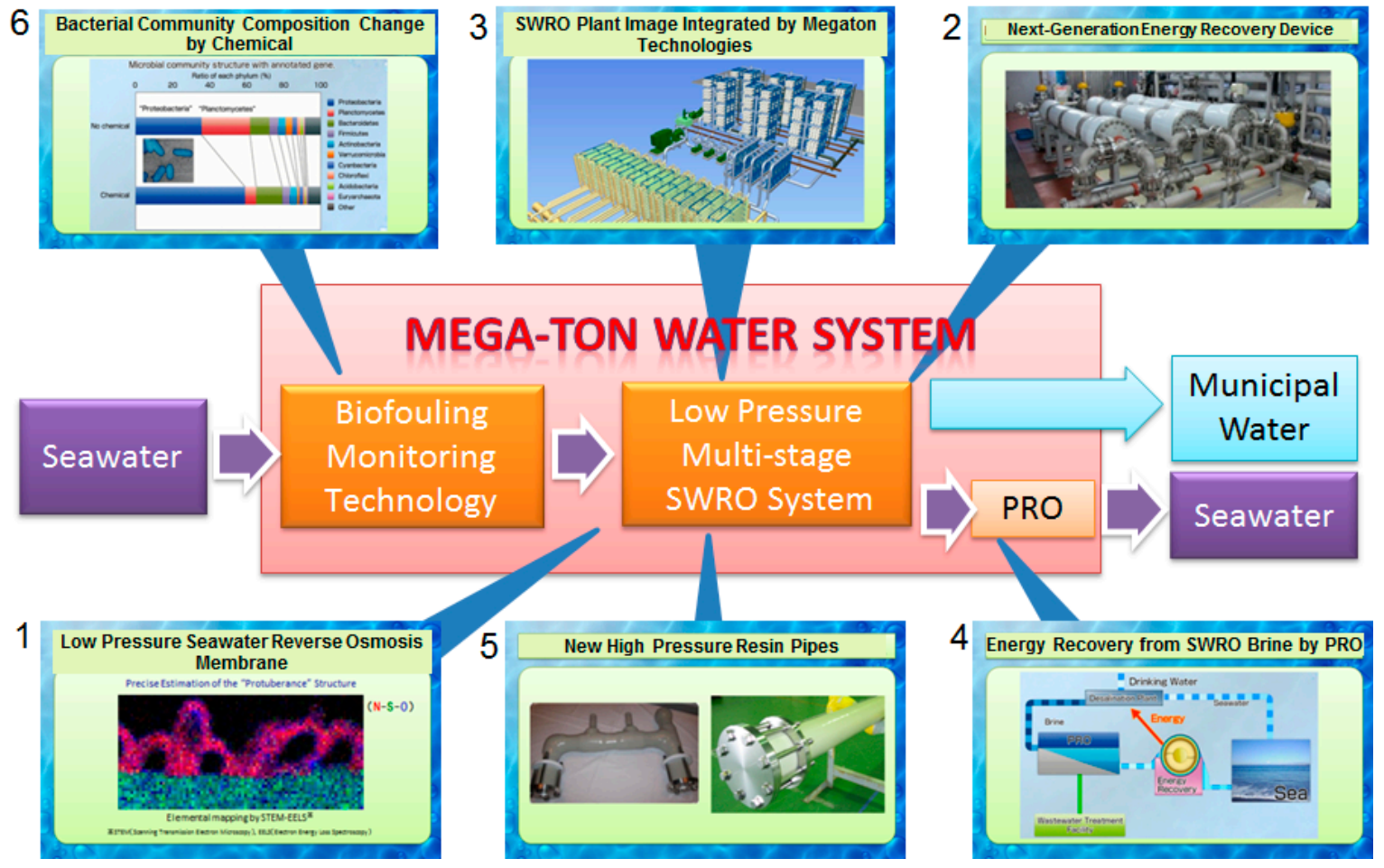

Figure 3. Outputs of "Mega-ton Water System" as six indispensable technologies for the 21st century. 
The output from the technological development of this project applies to the 1,000,000 $\mathrm{m}^{3} / \mathrm{d}$ SWRO system ("Mega-ton Water System"). This paper describes the biofouling monitoring technology of the "Mega-ton Water System" project and verifies the technology in the pilot and real plants in Saudi Arabia. Biofouling monitoring technology can be used to improve plant operation reliability by solving the biofouling problem of RO plants. It also contributes to reducing the environmental impact and water production costs by chemical-free injection. Four key technologies of the "Mega-ton Water System" are shown in Figure 3 and were verified at a pilot plant at a scale of $500 \mathrm{~m}^{3} /$ day, at the Desalination Technologies Research Institute (DTRI)/Saline Water Conversion Corporation (SWCC), Jubail in Saudi Arabia [4,5].

\section{Results and Discussion}

\subsection{Reliable Seawater Desalination System for Biofouling}

\subsubsection{History of Anti-Biofouling Trails for SWRO (Seawater Reverse Osmosis) System}

In the last ten years, there has been greater awareness of the need to preserve the environment, and there have been efforts to reduce the amount of chemically treated seawater discharged from desalination plants to lessen the ecological impact [6]. However, it was unfortunate that even now implementation with concrete scientific and technological solution to these issues was not forthcoming, even though the number of SWRO plants increased and large SWRO plants expanded rapidly. In the SWRO process, excessive growth of biomass affects water production and increases plant operation costs. About $40 \%$ of SWRO plants suffer from biofouling problems, and in the Middle East, it is about $70 \%$ [7]. There is a strong demand to develop more cost-effective feed-water intake and pretreatment techniques that can minimize biofouling and improve plant operations.

Sterilization of marine bacteria was considered effective for preventing biofouling of RO membranes, so continuous chlorination was applied (Figure 4). However, intermittent chlorination has now been found to be a more efficient method of SWRO biofouling control than continuous chlorination. The addition of chlorine is reported to be a trigger of biofouling [8-11]. The number of bacteria rapidly increases immediately after de-chlorination by SBS (sodium bisulfite) dosing. It is considered that chlorine added in raw water oxidizes natural organic matter (NOM) and microorganisms, and produces compounds that are easily assimilated by microorganisms. In addition, microorganisms exposed to chlorine might produce extracellular polymeric substances (EPS) accidentally or genetically as a defense mechanism and promote biofouling. The consumption of SBS has been found to increase with the SWRO plant operation time. There was a SWRO plant controlled the amount of SBS dosing in accordance with the RO brine levels. On one occasion, the decrease in concentration of SBS in the RO brine was observed, and so the level of SBS dosing amount upstream of the RO was increased. However, as time elapsed, the SBS concentration in the RO brine decreased again. This situation continued, and finally, a large amount of SBS was added to the system, and at the same time, RO differential pressure increased drastically. The result of the RO element autopsy showed the membrane surface covered with yellow foulant and Thiobacillus, which is a type of sulfur-oxidizing bacterium that can utilize reduced sulfur compounds, such as SBS, as an energy source, which indicates that the SBS alone can also be a trigger of biofouling [11]. However, there are no data that show direct evidence and quantitative impact of chlorination/de-chlorination on SWRO biofouling. To minimize biofouling, pretreatment processes will need to be established. The quantitative influence and mechanisms of chemical additives on the biofouling need clarifying. 
Conventional SWRO System (1990 2000)
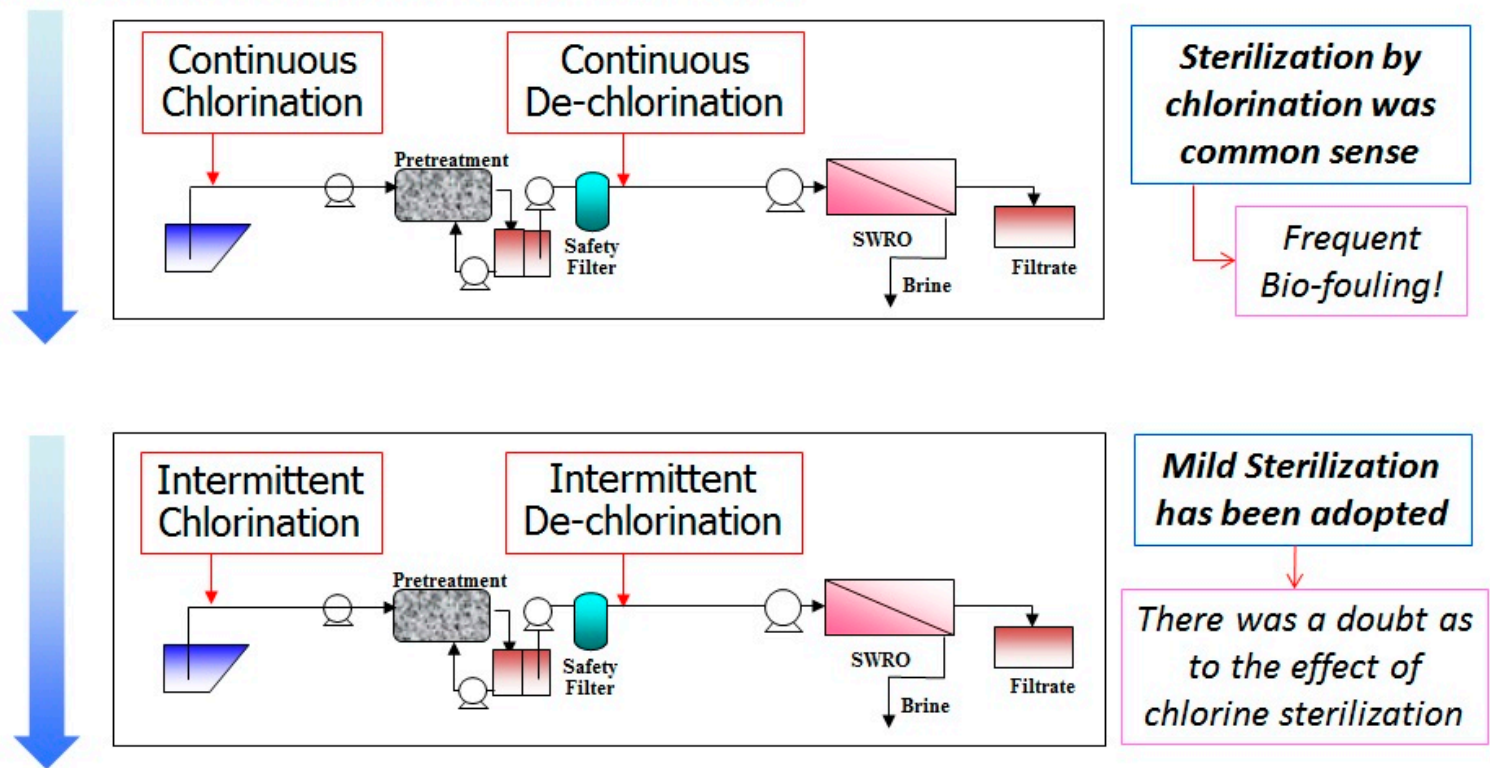

\section{Future SWRO System (2017 )}

Figure 4. History of anti-biofouling trials for SWRO (Seawater Reverse Osmosis) system.

\subsubsection{Sterilization Effect by Chlorination on Marine Bacteria is Limited}

The influence of chlorination on marine bacteria was evaluated by batch testing of seawater samples collected from Tokyo Bay. Cell abundance was enumerated by plate culture method using marine agar (Difco) and by direct microscopic observations after cells were stained with 4', 6-diamidino-2-phenylindole (DAPI), LIVE/DEAD BacLight kit (Invitrogen, Waltham, Massachusetts), and CTC rapid staining kit (Dojindo Laboratories, Kumamoto, Japan). The plate culture method is a convenient method; however, it is known that many bacteria are living but cannot be cultured (viable but nonculturable, VBNC) in seawater. In general, the number of bacteria obtained by the plate culture method is one to two orders of magnitude lower than the number of bacteria present. Therefore, to accurately evaluate the influence of chlorine addition on marine bacteria, both methods were used. For microscopic counting, samples were collected on black polycarbonate filters $(0.22 \mu \mathrm{m}$-pore-size Nuclepore, GE Healthcare Japan, Tokyo, Japan), of which the abundance was determined using an Olympus BX-51 epifluorescence microscope under UV excitation. Figure 5 shows the proportions of bacteria before and after hypochlorite treatment in processing with $2.5 \mathrm{mg} / \mathrm{L}$. Compared to the results of microscopic fluorescence observation, only $1 \sim 3 \%$ of the bacteria in seawater were detected by the conventional plate count method. The results of a bacterial viability assay, by direct microscopic counting, clearly show that many bacteria are still alive after chlorination at $2.5 \mathrm{mg} / \mathrm{L}$. These results indicate that the disinfection efficacy can be overestimated by the plate count method and much higher numbers of marine bacteria can survive after chlorination than expected. The growth of the remaining live marine bacteria might be due to the increased amount of easily accessible organic carbon produced by the degradation of the dead bacteria and natural organic matter. 


\section{Conventionalmethod (Plate count method)}

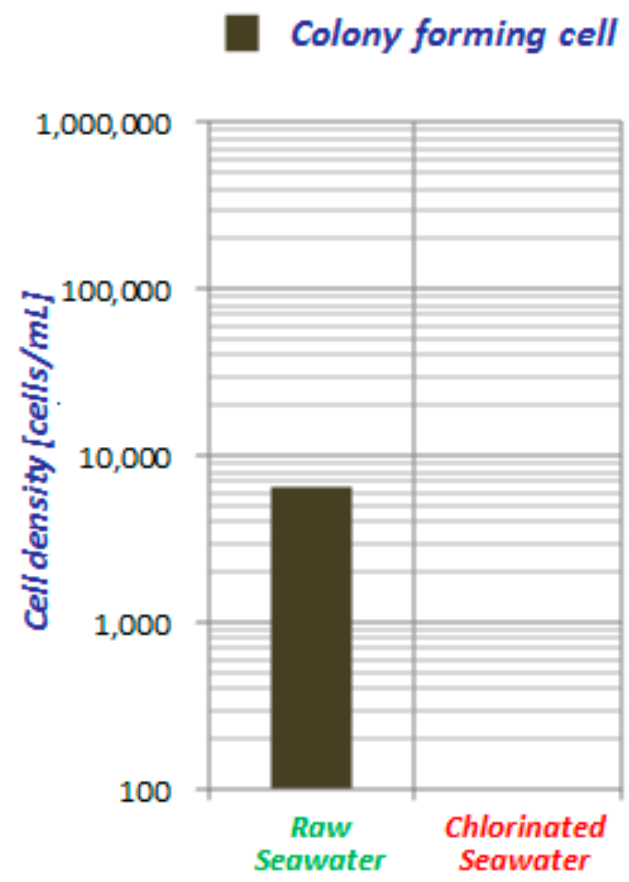

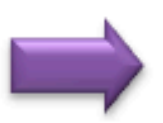

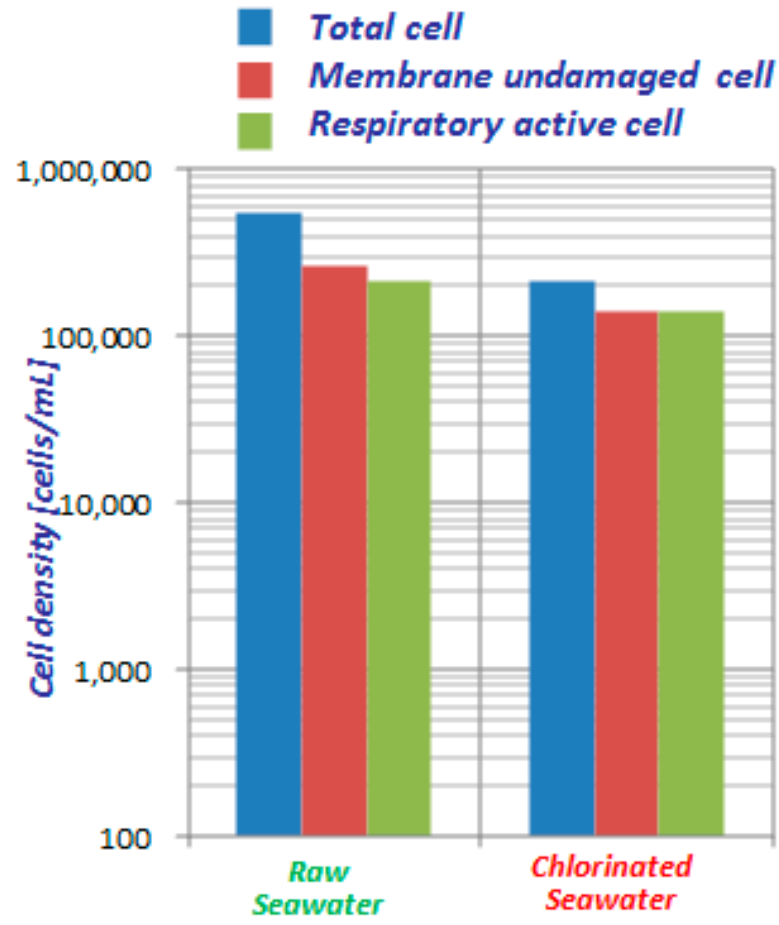

Figure 5. The sterilization effect by chlorination is limited.

\subsubsection{Membrane Biofilm Formation Rate (mBFR)}

To evaluate the biofouling potential of the $\mathrm{RO}$ fed seawater, biofilm growth monitoring devices, and seawater collection from a branching pipe just upstream of the high-pressure pump, were undertaken at each pilot unit [12]. Original biofilm growth monitoring devices were developed by Van der Kooij et al. (1995) to evaluate the biofilm formation rate (BFR), which use Glass or Teflon rings as the biofilm formation base and ultra-sonic equipment for collecting the biofilm [13-15]. We modified the original BFR measuring protocol as shown in Figure 6 [16]. To increase the accuracy and reliability of the biofilm formation evaluation, the biofilm formation base was changed from glass/Teflon rings to a cut piece of RO membrane. Biofilm was collected by wiping off the deposit using a sterilized swab and then suspending the deposit in $1 \mathrm{ml}$ of distilled water. The flow container of mBFR was composed of consecutively-connected separable opaque plastic short columns, and a cut piece of RO membrane was installed in each short column, this produces less contaminant and damage of the biofilm carrier. Two unit columns were periodically sampled from existing columns by twisting to perform an Adenosine Triphosphate (ATP) measurement of a sample of biofilm on the reverse osmosis membrane. The portable analysis device Lumitester (registered trademark) C-100 (product of Kikkoman Corp.) and the dedicated reagent kit CheckLite 250 Plus (product of Kikkoman Corp.) were used for the ATP measurement. By dividing the ATP total amount by the wiped area, the ATP amount per unit surface of the biofilm formation base material was detected. The mBFR values were obtained from the slopes of the linear relationships between biomass and exposure time. 

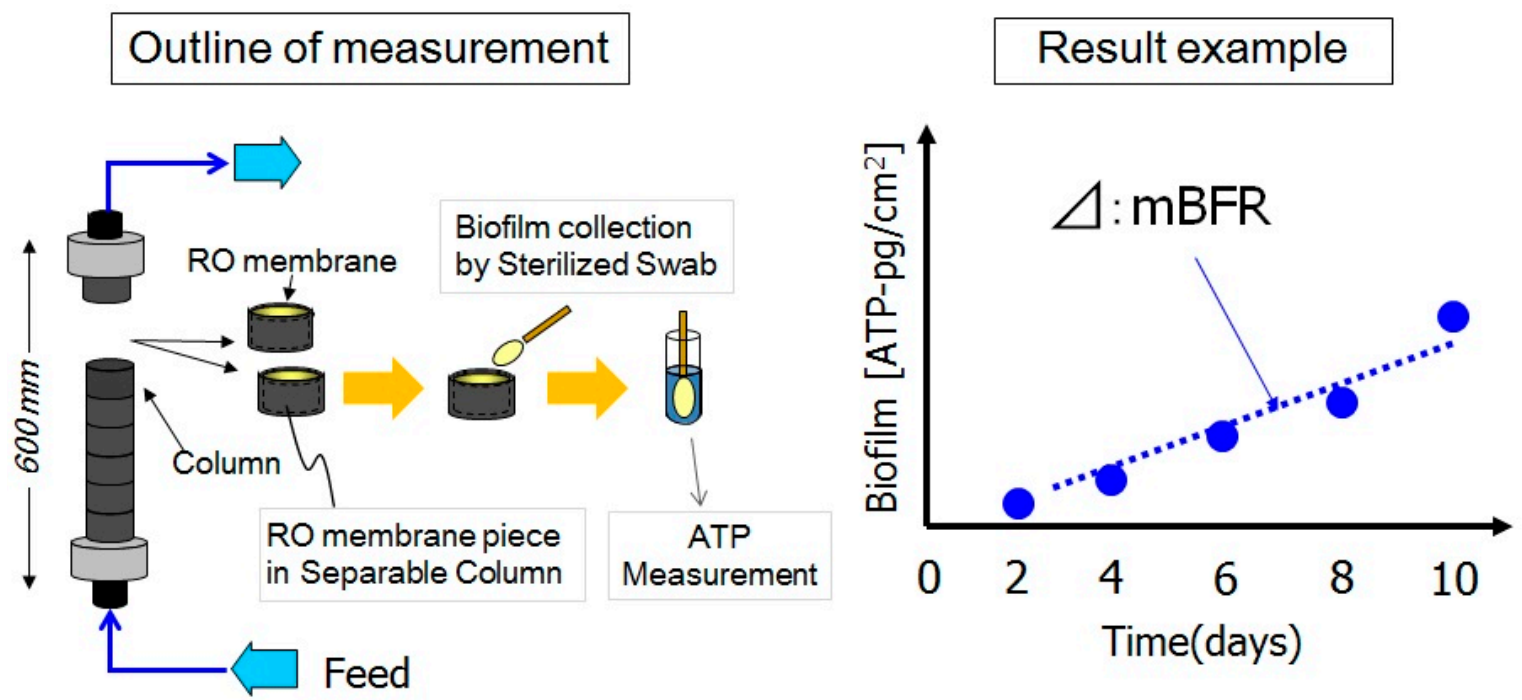

Figure 6. Method of measuring mBFR (Membrane Biofilm Formation Rate).

\subsubsection{Chlorine Sterilization Triggers Biofouling}

The filled square and circle in Figure 7 show the variation over time of the RO feed-brine differential pressure (DP) with and without chlorination and de-chlorination, respectively. Without the chemical addition, RO feed-brine DP was unchanged during the operation (filled circle). On the other hand, for the chlorinated/de-chlorinated unit, RO feed-brine DP increased sharply after 90 days of operation (filled square). These results demonstrate the negative impact of chlorination/ de-chlorination on SWRO operation.

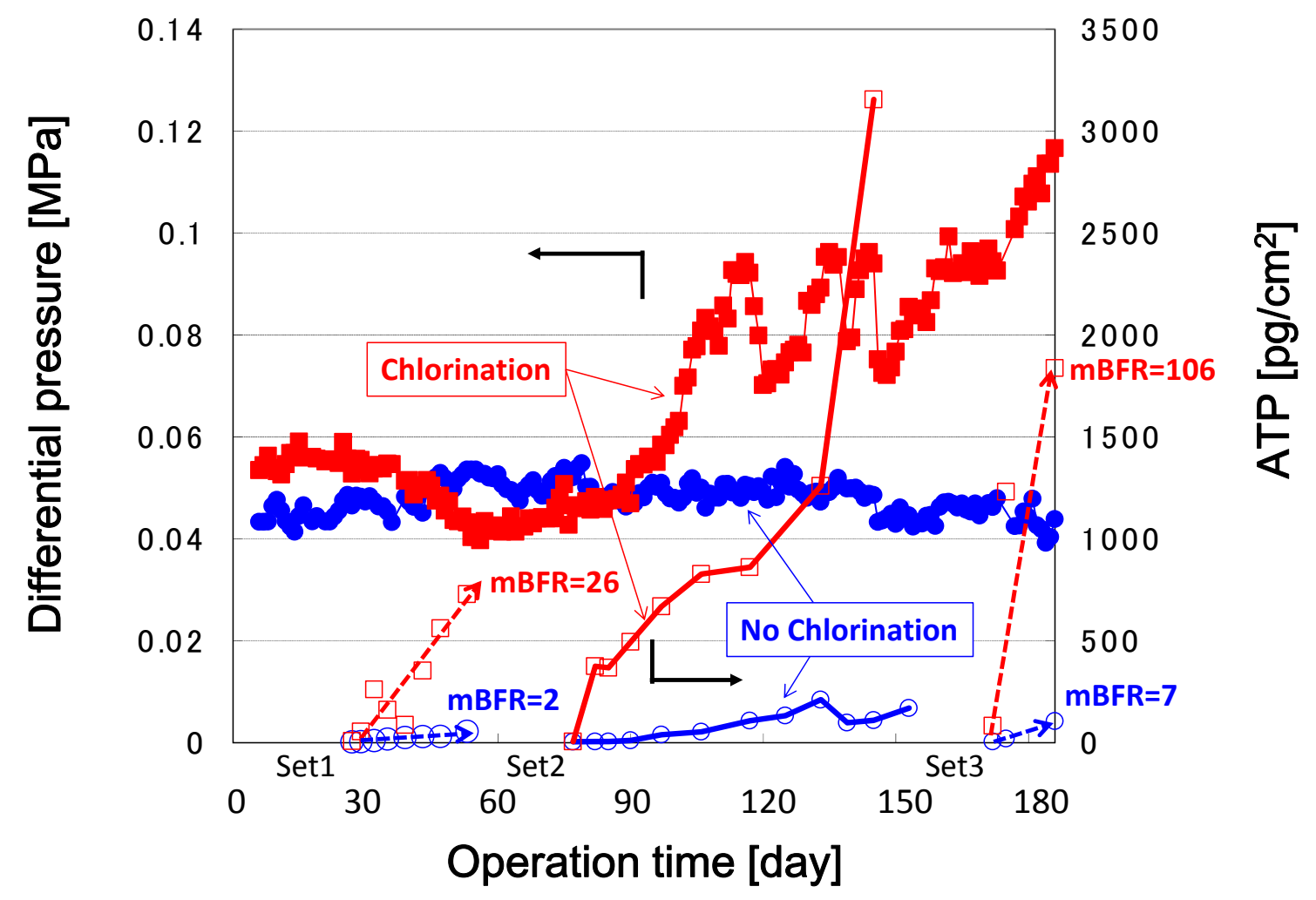

Figure 7. Chlorine sterilization triggers biofouling.

The open square and circle in Figure 7 show the variation over time of the ATP amount on the surface of a cut piece of the RO membrane in the MBFR biofilm monitor of the pilot test with 
and without chlorination and de-chlorination, respectively. The biofilm formation rate was very low for the non-chlorination and de-chlorination unit (open circle), suggesting that the quality of surface seawater in this area was fine during this test period. On the other hand, for the unit with continuous chlorination/de-chlorination (open square), the mBFR value was more than ten times higher than that of the non-chlorination and de-chlorination unit, and reproducible results were obtained. The combined data of the RO differential pressure and the biofilm (ATP) formation trend clearly verify not only the negative impact of continuous chlorination and de-chlorination on biofouling but also the reliability of $\mathrm{mBFR}$ as RO biofouling prediction and explanation indicators.

\subsubsection{The Effect of Chemical Addition on Microbial Community Structures}

Microbial community structure of RO membrane biofilms of chemical and non-chemical units was analyzed using a next-generation DNA sequencer at the phylum level. More seawater desalination plants are expected to employ operational monitoring technology using mBFR in the future. The effects of chemical addition on microbial community structures of the RO membrane biofilms of the chemical and the non-chemical units were analyzed using a next-generation DNA sequencer. The addition of sodium hypochlorite and sodium bisulfite greatly affected the microbial community structures of the SWRO biofilms. Proteobacteria, Planctomycetes and Bacteroidetes were dominant in the biofilms of both the chemical and the non-chemical units as shown in (Figure 8) [17].

\section{Ratio of each phylum (\%)}

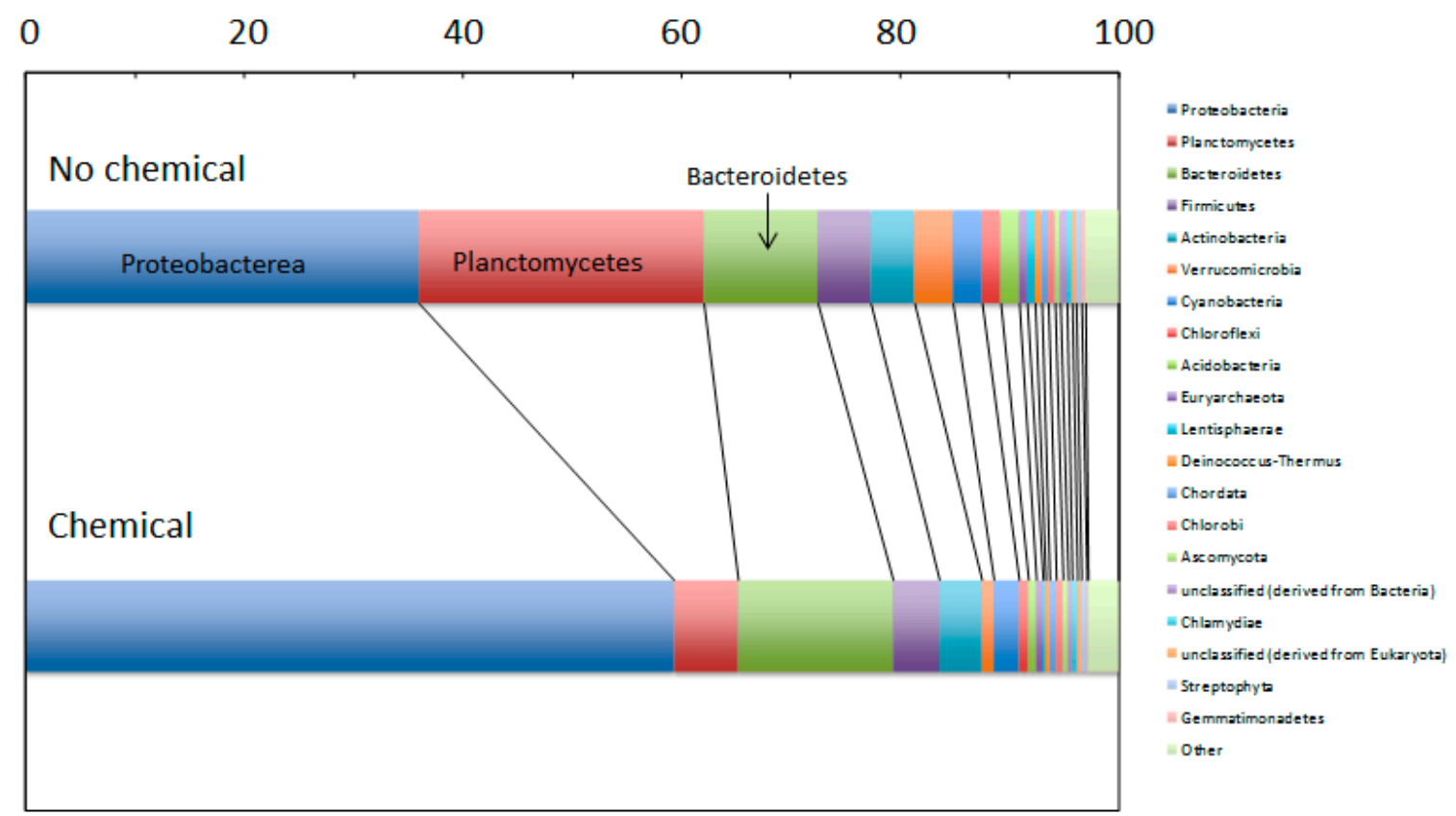

Figure 8. Microbial community structure of RO foulants at the Phylum level.

2.1.6. Comparison of Conventional Process and New Process Proposed by “Mega-ton Water System" Project

The design concept for the ideal pretreatment system for future SWRO desalination plants is shown in Figure 9. The quality of the seawater is evaluated by the biofouling monitoring index mBFR. For the clear seawater area, the SWRO system with simple pretreatment, for example, a sand filter or UF followed by a cartridge filter, with no chemical dosing seems to be pertinent for stable SWRO operation. For highly polluted seawater regions, elaborate pretreatment processes suitable for removal of soluble easily biodegradable organics, for example, dissolved air flotation systems followed by 
dual media filters, might be necessary. The optimum pretreatment processes suitable for the seawater region can be evaluated and verified by mBFR during pilot testing.

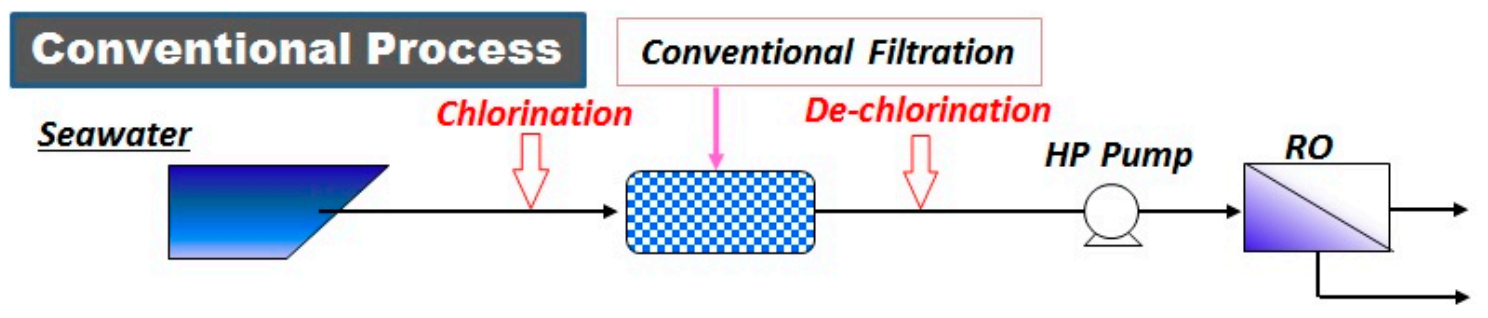

\section{New Process proposed by "Mega-ton Water System" project}

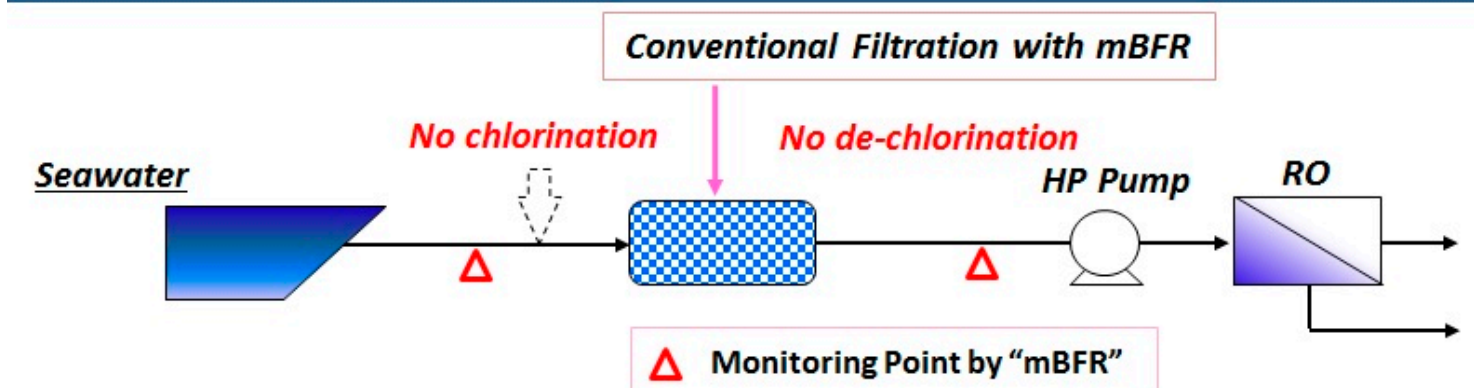

Figure 9. Comparison of conventional process and new process proposed by the "Mega-ton Water System" project.

Recently, we learned that a measuring method similar to that of ATP in seawater had been presented at the International Desalination Association (IDA) World Congress at Sao Paulo, Brazil [18].

2.2. Verification of Biofouling Monitoring Technology in Arabian Gulf, Most Severe Biofouling Area and in the Red Sea in Saudi Arabia

Further progress of the "Mega-ton Water System" was reported at the 12th SWA-APDA Joint Conference held on 11th July 2018, during Singapore International Water Week (SIWW) [5].

This presentation included mainly two research items:

(1) Verification of biofouling monitoring technology in the Arabian Gulf Sea and the Red Sea in Saudi Arabia, as shown in Figure 3, as biofouling monitoring technology [2].

(2) High-performance system for low-cost seawater using other Mega-ton Technologies are shown in Figure 3 as low-pressure multistage SWRO systems [4].

(A) High water recovery system by two-stage one pass up to $60 \%$.

(B) Flux equalization by optimization of vessel configuration (two elements in one vessel).

(C) High-energy recovery by ERD.

(D) Newly developed polyamide membrane (TM820V-400) by Toray was used in this system.

(E) Pre-treatment is DMF (Dual Media Filter).

The first item was included in this paper as follows.

2.2.1. Pilot Plant Verification ( $500 \mathrm{~m}^{3} /$ day) in the Arabian Gulf

SWCC/DTRI, Toray Industries, Inc. and Hitachi, Ltd. collaborated in the evaluation of the advanced design system and technologies, including biofouling monitoring technology developed by the "Mega-ton Water" project during December 2016-January 2018.

Al-Jubail is located on the Arabian Gulf, which is subject to high salinity (4.6\%) and large temperature variations $\left(14\right.$ to $\left.37^{\circ} \mathrm{C}\right)$ as shown in Figure 10 [5]. 


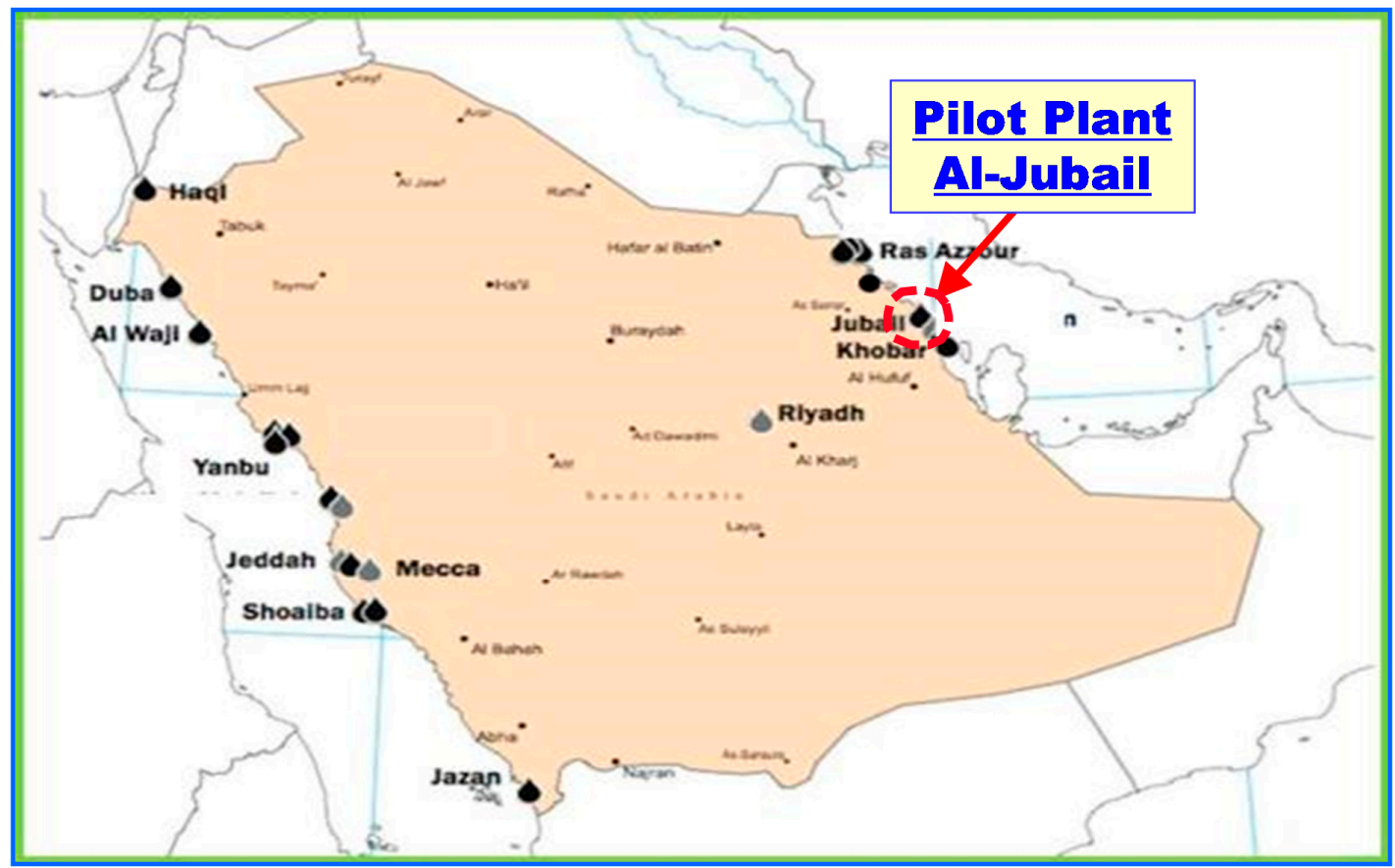

Figure 10. Sites of pilot plant verification and full plant verification of the NEDO-SWCC Demonstration Project in Saudi Arabia.

Stable operation of no chlorination and no SBS addition by using mBFR technology was confirmed during one year of operation. And targets of expected energy consumption and operational costs were also verified during one year of operation.

2.2.2. Full Plant Verification of NEDO-SWCC Demonstration Project $\left(10,000 \mathrm{~m}^{3} /\right.$ day $)$ at the Red Sea, Ummluji, Saudi Arabia

The next step of the post-megaton project is the full plant verification of the New Energy and Industrial Technology Development Organization (NEDO)-SWCC Demonstration Project for Energy Saving Seawater Desalination Technology in Saudi Arabia. Hitachi and Toray have been commissioned by NEDO to Implement the Demonstration Project for a full-scale Energy Saving Seawater RO System in the full plant scale in Saudi Arabia. The Saline Water Conversion Corporation (SWCC) is a partner in the project. The demonstration size is $10,000 \mathrm{~m}^{3}$ / day, running a seawater RO system using "Mega-ton Water System" technologies. The project is located in Ummluji, Saudi Arabia as shown in Figure 10 [5]. The demonstration period is April 2018-March 2023 (5 years).

The targets of this project are as follows [5]:

(1) Reduce energy consumption by around $20 \%$ compared to that of conventional seawater desalination plants applying RO membranes.

(2) Reduce the construction cost by reducing the capacity of the pretreatment facilities, which will be enabled by lowering the seawater intake.

(3) Biofouling monitoring technology using mBFR is applied to this project.

\section{Conclusions}

One of the research themes of the "Mega-ton Water System" project is biofouling monitoring technology related to reliable plant operation for sustainable desalination in the 21st century.

1. A reliable seawater desalination system based on membrane technology and biotechnology for considering environmental impacts were established as an innovative paradigm shift of the biofouling concept. 
2. We confirmed that the chemical addition of chlorine and SBS triggers biofouling.

3. Biofouling monitoring technology using mBFR was a good indicator of reliable seawater desalination system design and operation.

4. This biofouling monitoring technology using mBFR was verified in a pilot test, located in $\mathrm{Al}$ Jubail, DTRI and Saudi Arabia during one year.

5. The next step of the post-megaton project is the verification of this technology at a full-scale plant-10,000 $\mathrm{m}^{3}$ / day in Ummluji, Saudi Arabia.

Author Contributions: M.K. and H.T. supervised the technical activities and the writing of the paper. Y.I. designed and conducted the experiments to evaluate the chlorine sterilization effect on SWRO biofouling using mBFR with his group. Lab and Pilot experiments of marine bacteria analysis were performed by Y.I. group, collaboration with K. Kogure groups, University of Tokyo. All authors contributed to the interpretation and discussion of the experimental results.

Funding: The "Mega-ton Water System" research in this report was funded by a grant from Japan Society for the Promotion of Science (JSPS) through the FIRST Program initiated by the Council for Science and Technology Policy (CSTP).

Acknowledgments: We sincerely appreciate the technologies mentioned in this study that were developed by the "Mega-ton Water System" research project, which were granted by the Japanese Society for the Promotion of Science (JSPS) through the "Funding Program for World-Leading Innovative Research \& Development on Science and Technology(FIRST Program)" initiated by the Council for Science and Technology Policy(CSTP). We also sincerely appreciate the New Energy and Industrial Technology Development Organization (NEDO) and their support of the "Mega-ton Water System" project. The part of this study is a joint research of Saline Water Conversion Corporation, Desalination Technologies Research Institute (SWCC/DTRI), Hitachi, Ltd. and Toray Industries, Inc.

Conflicts of Interest: The authors declare no conflict of interest.

\section{References}

1. International Desalination Association. Global Water Intelligence; DesalData 2016 Plant Inventory Report; International Desalination Association: Oxford, UK, 2016.

2. Kurihara, M.; Takeuchi, H. Earth-friendly Seawater Desalination System required in 21st Century. Chem. Eng. Technol. 2018, 41, 401-412. [CrossRef]

3. Kurihara, M.; Hanakawa, M. Mega-ton Water System: Japanese national research and development project on seawater desalination and wastewater reclamation. Desalination 2013, 308, 131-137. [CrossRef]

4. Kurihara, M.; Takeuchi, H. The Next Generation Energy Efficient Membrane Desalination System with Advanced Key Technologies: "Mega-ton Water System", Current Trends and Future Development on (Bio-) Membranes 1st Edition-Membrane Desalination System: The Next Generation; Elsevier: Amsterdam, The Netherlands, 2018; eBook ISBN: 9780128135525 , Paper ISBN 9780128135518.

5. Kurihara, M.; Kurokawa, H. Further Progress of "Mega-ton Water System". In Proceedings of the 12th SWA-APDA Joint Conference, Singapore, 11 July 2018.

6. Lattemann, S.; Höpner, T. Environmental impact and impact assessment of seawater desalination. Desalination 2008, 220, 1-15. [CrossRef]

7. Khedr, M.G. Membrane fouling problems in reverse osmosis desalination applications. Int. Desalin. Water Reuse Q. 2000, 10, 259-267.

8. Baker, J.S.; Dudley, L.Y. Biofouling in membrane systems-A review. Desalination 1998, 118, 81-90. [CrossRef]

9. Saeed, M.O.; Jamaluddin, A.T.; Tisan, I.A.; Lawrence, D.A.; Al-Amri, M.M.; Chida, K. Biofouling in a seawater reverse osmosis plant on the Red Sea coast, Saudi Arabia. Desalination 2000, 128, 177-190. [CrossRef]

10. Hamida, A.B.; Moch, I., Jr. Controlling biological fouling in open sea intake RO plants without continuous chlorination. Desalin. Water Reuse 1996, 6, 40-45.

11. Kimura, T.; Ito, Y.; Nakaoki, Y. Innovative Biofouling Prevention on Seawater Desalination Reverse Osmosis Membrane; International Desalination Association: Oxford, UK, 2001.

12. Ito, Y.; Hanada, S.; Kitade, T.; Tanaka, Y.; Kurihara, M. Clarification of Impact of Biofouling Triggered by Chemical Addition; IDAWC: Tianjin, China, 2013.

13. Van der Kooij, D.; Veenendaal, H.R.; Baars-Lorist, C.; Van der Klift, D.; Drost, Y.C. Biofilm formation on surface of glass and teflon exposed to treated water. Water Res. 1995, 29, 1655-1662. [CrossRef] 
14. Van der Kooij, D.; Vrouwenvelder, J.S.; Veenendaal, H.R. Kinetic aspects of biofilm formation on surfaces exposed to drinking water. Water Sci. Technol. 1995, 32, 61-65. [CrossRef]

15. Vrouwenvelder, J.S.; Van der Kooij, D. Diagnosis, prediction and prevention of biofouling of NF and RO membranes. Desalination 2001, 139, 65-71. [CrossRef]

16. Ito, Y.; Kantan, S.; Maeda, T.; Okubo, K.; Taniguchi, M. Innovative Biofouling Monitoring Device and its Criteria for Reverse Osmosis plant Operation and Optimization; IDAWC: San Diego, CA, USA, 2015.

17. Kogure, K. Poster session, Bacterial community structure of RO foulant at phylum level. In Proceedings of the International Symposium on FIRST Program “Mega-ton Water System”, Tokyo, Japan, 21-22 November 2013.

18. Dhakal, N.; Salinas-Rodriguez, S.; Knops, F.; Schippers, J.; Kennedy, M. Ultrafiltration as a pretreatment for seawater reverse osmosis during algal bloom. In Proceedings of the International Desalination Association (IDA) World Congress 2017, Sao Paulo, Brazil, 15-20 October 2017.

2018 by the authors. Licensee MDPI, Basel, Switzerland. This article is an open access article distributed under the terms and conditions of the Creative Commons Attribution (CC BY) license (http://creativecommons.org/licenses/by/4.0/). 